\title{
Movement in the Afrikaans left periphery: A view from anti- locality
}

\author{
Robyn Berghoff \\ Department of General Linguistics, Stellenbosch University, South Africa \\ E-mail: berghoff@sun.ac.za
}

\begin{abstract}
It has been convincingly argued that the so-called "left periphery" of the sentence makes available multiple positions which host topicalised and focalised phrases, among other elements. Projections in the C-domain have been shown to have a fixed ordering, the violation of which results in ungrammaticality. Rizzi (1997) provides a template that specifies this ordering. Botha and Oosthuizen (2009) examine this template's ability to account for ordering phenomena in the Afrikaans left periphery and make certain necessary adjustments to Rizzi's template to account for their data. This short paper takes Botha and Oosthuizen's observations regarding the (im)possibility of a certain ordering in the Afrikaans $\mathrm{CP}$ as a case in point. Broadly put, the paper's premise is that although the template provided for the Afrikaans CP may be descriptively adequate, in that it can accommodate and predict possible orderings, it falls short in that it does not account for why such a template should exist. That is, the template itself does not explain why certain orderings are permissible and others are not. It is the paper's modest aim to test the ability of one theoretical perspective, namely Grohmann's (2003) theory of anti-locality, to account for the illegality of a particular ordering in the Afrikaans CP. Antilocality's ban on 'too local' movement is shown to predict the illicitness of this ordering. Due to the paper's limited scope, the analysis is not extended to other constructions. Its aim is to prompt further efforts to account for the observed ordering in the CP domain, and it offers the theory of anti-locality as a possible starting point for these efforts.
\end{abstract}

Keywords: Afrikaans, left periphery, anti-locality

\section{Introduction}

Since the late 1990s, it has been broadly accepted that the functional category of complementiser makes available multiple positions at the so-called "left periphery" of the sentence that can be occupied by moved elements. Perhaps the best-known analysis of the structure of the left periphery is that of Rizzi (1997); an earlier proposal is that of Hoekstra and Zwart (1994), and a more recent account has been offered by Benincà and Poletto (2004).

Botha and Oosthuizen (2009) review these proposals' ability to account for ordering phenomena in the Afrikaans complementiser phrase (CP). These authors put forward some 
modifications to Rizzi's structure that are necessary to account for the Afrikaans data and ultimately propose a template for the Afrikaans CP. However, although this template may be empirically adequate in that it accommodates the grammatical structures in the language, it falls short in explaining why such a template should exist. That is to say, we lack a theoretical motivation for why certain orderings within the Afrikaans CP are illicit.

This short paper makes an initial attempt to address this shortcoming by offering a view of one particular illicit ordering in the Afrikaans CP through the theoretical lens of anti-locality (Grohmann 2003). Essentially, it argues that this ordering is illicit because it would involve 'too local' movement.

After recapping Botha and Oosthuizen's (2009) review of past proposals for the structure of the left periphery, the paper lays out these authors' proposed modifications to this structure to accommodate the Afrikaans data, drawing on Benincà and Poletto (2004). Subsequently, it reviews one theoretical explanation for the ordering that is obtained: Abels' (2012) argument from locality. After showing that this account also fails to align with the Afrikaans ordering, an explanation from an anti-locality perspective is proposed.

\section{Earlier proposals on the structure of $\mathbf{C P}$}

Botha and Oosthuizen (2009) review three proposals regarding the structure of CP: that drawn from Government and Binding (GB) theory, Hoekstra and Zwart's (1994) bipartite system, and Rizzi's 'fine structure of the left periphery'. This section recaps their exposition of the relevant ideas.

Under Government and Binding (GB) theory, the CP is said to make available one position, namely Spec,CP, which can be filled by (what is typically assumed to be) a base-generated leftdislocated (LD) element, a moved wh-element, a topicalised element, or a focalised element. Additional moved elements can adjoin to $\mathrm{CP}$, thus allowing more than one constituent to occur in the left periphery. However, adjunction is not possible in the case of verb-second (V2) languages like Afrikaans, given the constraint that only one constituent can precede the verb in these languages.

Examples involving elements in the left periphery are presented in (1)-(3). Here, focalised elements are identified by their incompatibility with a resumptive pronoun (Benincà 2001: 44). Thus, (3) is an example of focalisation (where capitalisation denotes emphasis ${ }^{1}$ ); (2) is an example of topicalisation; and (1) is an example of a moved wh-element. ${ }^{2}$ Henceforth, all examples are from Afrikaans or English, unless indicated otherwise.

Watter vrou het die man gister gesien?

which woman has the man yesterday seen

"Which woman did the man see yesterday?"

\footnotetext{
${ }^{1}$ Contrastive intonation, whilst not necessarily "immediate proof of [f]ocalisation" (Benincà 2001: 44), generally accurately identifies a focalised element.

${ }^{2}$ As Botha and Oosthuizen (2009: 37) note, in Afrikaans both left-dislocated and topicalised phrases occur with a resumptive pronoun; these constructions are thus superficially identical in the language. We therefore do not distinguish further between left-dislocation and topicalisation here, and refer simply to "topicalisation".
} 


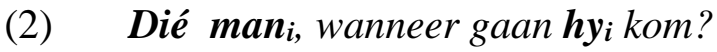

Botha and Oosthuizen (2009: 21)

that man when go he come

"That man, when will he come?"

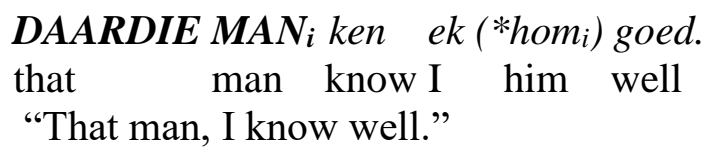

Botha and Oosthuizen (2009: 26)

The primary shortcoming of this analysis is the occurrence of constructions in V2 languages in which either topicalised, focalised, or wh-elements co-occur, despite the stipulation that adjunction to $\mathrm{CP}$ is not possible in these languages. This means that examples such as (4) and (5), incorporating both a topicalised element and a wh-element and focalised element, respectively, cannot be accommodated.

(4) Daardie mani, watter vrou het hy gister gesien?

that man which woman have he yesterday seen

"That man, which woman did he see yesterday?"

\section{Daardie mani, $_{\text {, }} \boldsymbol{Y}_{\boldsymbol{i}} \boldsymbol{M A}$ ken ek goed. \\ that man his mother know I well \\ "That man, his mother I know well."}

Furthermore, constructions in which two C-heads co-occur are not predicted, although such constructions occur in both Afrikaans and Dutch (cf. Hoekstra and Zwart 1994 in this regard). The example in (6) is from Oosthuizen (1994: 165).
a. Ek twyfel of dat hulle sal kom.
I doubt if that they will come
"I doubt that they will come."

On this basis, it is argued that the GB account of the structure of the CP requires modification. Hoekstra and Zwart's (1994) proposal, aimed at accommodating examples such as (4)-(6), is to divide the single $\mathrm{C}$-head into two heads, each with their own projection; one being the locus of moved wh-elements (a so-called "WhP"), and the other home to topicalised and focalised elements (referred to as "TopP"). Their proposal can thus account both for (6) and for examples such as (4) and (5), with (4) being attributed a structure represented simplistically as (7).

\section{[ TорP Daardie man [ $_{\text {[hP }}$ watter vrou [ het hy $y_{i}$ gister gesien? ]]]}

However, in the case of (8), where two topicalised elements (my pa and sy siekte) occur together with a $w h$-phrase, their bipartite split of the $\mathrm{CP}$ is inadequate. ${ }^{3}$

\footnotetext{
${ }^{3}$ An alternative suggestion that would allow the CP to consist of fewer, or even a single, position(s) whilst still accommodating structures like (8) would be to argue that multiple fronted elements such as my pa and sy siekte in fact form one constituent and attach as such to Spec,CP. A similar proposal occurs in the guise of CP-recursion, which allows for additional CPs to be introduced. Benincà (2001: 41) argues that, were such a solution plausible, we would not expect any rigid ordering amongst elements in the left periphery. Such an ordering is indeed to be found: in (8), Sy siekte, my pa... is ungrammatical, suggesting that there is an ordering constraint at work (cf. Frascarelli and Hinterhoelzl (2007) for discussion of topic ordering in German and Italian and Badan and Del Gobbo (2011) regarding Mandarin Chinese). Although this point is not pursued further in this paper, it is noted
} 
My $\mathbf{p a}_{i}$, sy siekte $_{j}$, wanneer gaan hy $y_{i}$ dit $_{j}$ maar net aanvaar? my dad his illness when go he it but just accept "My dad, his illness, when is he just going to accept it?"

It is thus necessary to explore the possibility that the CP makes available more than two positions. Botha and Oosthuizen (2009) motivate this proposal further by arguing that the semantic and pragmatic distinctions between focalised, topicalised, and wh-phrases warrant distinguishing between the positions these phrases occupy.

Rizzi's $(1997,2004)$ proposes a structure of the C-domain that incorporates finer distinctions; dividing the $\mathrm{CP}$ into four functional heads, each with their own projection. In his analysis, the $\mathrm{CP}$ is made up of a ForceP (ForP), a TopicP (TopP), a FocusP (FocP), and a FinitenessP (FinP). This structure is represented in (9) below and discussed in the following subsections. Note that * represents potential for recursivity.

$$
[\text { ForP }[\text { TopP } *[\text { FocP }[\text { TopP * [ FinP }[\text { IP... ] ] ]]]] }
$$

TopP and FocP are available for topicalised and focalised elements, both of which were hosted by TopP in Hoekstra and Zwart's structure. As noted above, topicalised elements are compatible with a resumptive pronoun, but focalised direct objects are not (Botha and Oosthuizen 2009: 24). Thus, in (10a) witwyn is taken to occur under TopP. (10b)'s lack of resumptive pronoun (dit) renders the sentence ungrammatical (examples from Botha and Oosthuizen 2009: 24).

(10) a. Witwyn, ek kan dit $\boldsymbol{t}_{i}$ nie drink nie. white.wine I can that NEG drink NEG

b. * Witwyn, ek kan nie drink nie. white.wine I can NEG drink NEG "White wine, I can't drink."

Botha and Oosthuizen (2009: 24) also note that topicalisation in Afrikaans does not result in a change in word order, whereas focalisation does. ${ }^{4}$ Thus the contrast between (10c) and (10d), where witwyn is focalised in both sentences, but non-inverted (10c) is ungrammatical:
c. * WITWYN, ek kan nie drink nie. white.wine I can NEG drink NEG
d. WITWYN kan ek nie drink nie. white.wine can I NEG drink NEG

\footnotetext{
that it may also be possible to argue that this ordering arises from semantic/pragmatic considerations: topics, for example, as they establish what a sentence is about, may be expected to occur prior to focalised elements, which serve to introduce new information. The reader is referred to Neeleman et al. (2009) for an exposition of such an account.

${ }^{4}$ Botha and Oosthuizen (2009: 58) suggest this may be because TopP selects a Fin-head with a weak Tense feature that does not attract the verb. The reader is referred to their paper for further discussion of this matter.
} 
An additional distinction between topicalised and focalised elements can be made on discourse grounds. Topics are relationally given, in that they often are what a sentence or utterance is about (although cf. Frascarelli and Hinterhoelzl 2007 for discussion of the various kinds of topics), whereas focalised elements serve to introduce new information. This discourse-based distinction is revisited later in the paper.

The next projection to be considered, ForP, is argued to be the highest projection in the Cdomain. It is the locus for a complementiser that expresses the type of a sentence, i.e. whether it is a question, a declarative, an exclamative, and so forth (Rizzi 1997: 283).

ForP is illustrated along with a focalised phrase in (11) below (from Radford 2006: 209):

I am absolutely convinced [ $\mathrm{ForP}$ that [ ${ }_{\mathrm{F}} \mathrm{No}$ NO OTHER COLLEAGUE [ Foc' would [ IP he turn to ]]]].

FinP in its turn holds a Fin-head, which specifies whether its TP complement must be finite or infinite (Botha and Oosthuizen 2009: 44). Support for the existence of such a projection can be found in English, where the complementiser that takes a finite TP complement, whereas for takes a non-finite TP complement, as shown in (12).

\section{a. I hope that she understands. \\ b. I hope for her to understand.}

Later work of Rizzi's adds to the template given in (9) a ModP between the lower FocP and TopP, which hosts preposed adverbials. The contention that this ModP is distinct from TopP rests on Rizzi's (2004: 15) observation that, in contrast with genuine topics, preposed adverbials cannot naturally occur before $w h$-elements in questions. ${ }^{5}$ This is indicated in the Italian examples in (13) below. Preposed adverbials are thus argued to occur lower in the structure than the wh-element, which is located in FocP. However, as illustrated in (13b), Rizzi (2004: 16) also remarks that they are not allowed to occur directly below the wh-element.
a. ?? Rapidamente, che cosa hanno fatto?
rapidly what thing have.3PL do.3PL.PST
"Rapidly, what have they done?"
b. * Che cosa, rapidamente, hanno fatto?
what thing rapidly have.3PL do.3PL.PST
"What, rapidly, have they done?"

Int, in this template, is the position occupied by $w h$-elements that occur higher up (above FocP) in the $\mathrm{CP}$ and do not trigger inversion - for example, the Italian perché 'why'. Wh-elements of this type are argued to be base-generated in this higher position. The non-inverting behavior of perché is illustrated in (14).

\footnotetext{
${ }^{5}$ Although Rizzi (2004: 17) notes that there are in fact three positions in which preposed adverbials may occur: (i) the dedicated ModP; (ii) a genuine topic position "[i]n very special discourse contexts, i.e. when they have been mentioned in the immediately preceding discourse"; and (iii) the initial focus position.
} 
[ Int Perché, [ Topp il mio libro [ Gianni lo ha portator via ]]] why the my book Gianni it have.3SG take.3SG.PST away "Why, my book, Gianni took it away?"

Thus, the updated structure of the left periphery argued for in Rizzi (2004) has the form in (15). (15) adds to (9) the Int-projection, an additional TopP after Int, and ModP.

$$
[\text { ForP }[\text { TopP* }[\operatorname{Int}[\text { TopP* }[\text { FocP }[\operatorname{ModP} *[\operatorname{TopP} *[\text { FinP }[\text { IP... ] ] ]]]]]]] }
$$

To summarise, this section considered three proposed structures of the left periphery in light of data from Afrikaans: GB-theory's single-head analysis as it applies to V2 languages; Hoekstra and Zwart's (1994) bipartite analysis; and Rizzi's (2004) six-part analysis, which is an updated form of that author's (1997) four-part analysis. The first two analyses were shown to be too limited to accommodate the multiple elements that can be fronted in Afrikaans and other V2 languages. Rizzi's template, on the other hand, has proven to be useful in describing constructions in a number of different languages - although all of the examples given above are from the Indo-European family; see Paul (2000) for a discussion of topic and focus in Malagasy, and Aboh's (1999) analysis of Gungbe, which has overt Topic and Focus heads. The following section presents Botha and Oosthuizen's (2009) analyses of some Afrikaans data that do not conform to Rizzi's template.

\section{Botha and Oosthuizen's (2009) critique of Rizzi's structure: data from Afrikaans}

Botha and Oosthuizen (2009: 26) identify some incompatibilities between ordering in the Afrikaans CP and Rizzi's structure. The first, which is not discussed in this paper, is that Rizzi's template allows a TopP to occur below FocP; a configuration that results in ungrammaticality in Afrikaans - cf. *JAN, witwyn, dit kan hy nie drink nie (Jan, white.wine, that can he NEG drink NEG; Botha and Oosthuizen 2009:26). The second, for discussion of which the reader is also referred to Botha and Oosthuizen's paper, is that it is seemingly not possible for a ModP to intervene between FocP and the verb in Afrikaans - cf. ??Jan, WITWYN, rêrig, kan hy nie drink nie (Jan, WHITE.WINE, really, can he NEG drink NEG) vs. Jan, rêrig, WITWYN, kan hy nie drink nie (Jan, really, WHITE.WINE can he NEG drink NEG).

The point of difference focused on in this paper relates to the co-occurrence of a moved whelement and a focalised phrase. According to Rizzi (1997: 291), "[a] Wh operator in main questions is compatible with a Topic in a fixed order (Top Wh), whereas it is incompatible with a Focus". Because Rizzi posits only one FocP, which can host either a focalised element or a moved-wh element, these should be in complementary distribution.

However, Botha and Oosthuizen argue that some Afrikaans examples undermine this argument. One such example is (16), for which Botha and Oosthuizen (2009: 27) posit the following structure: 


$$
\begin{aligned}
& \text { [ TopP Die } \text { man }_{i},\left[\text { FocP } \text { GISTER}_{j},\left[\text { FocP watter vrou [ het hy } y_{i}\left(\text { toe }_{j}\right) \text { aangerand? ] ] ] }\right]^{6}\right. \\
& \text { the man yesterday which woman have he then assaulted } \\
& \text { "The man, yesterday, which woman did he assault (then)?" }
\end{aligned}
$$

In (16), Botha and Oosthuizen argue that gister can be either topicalised or focalised, as indicated by the optionality of the resumptive pronoun toe "then". They provide both syntactic and information-structural support for the claim that gister can be focalised.

In terms of syntactic motivations, the authors (2009: 28) refer to an example in Hoekstra and Zwart (1994), and argue that it must be possible for focalised and wh-elements to co-occur in the C-domain, at least in cases where the focalised element moves from a subordinate clause to the left periphery of the main clause. The example is as follows:
a. MORGEN weet ik hoe laat ik kan. tomorrow know I how late I can "I know what time I can (be there/do something) tomorrow."
b. $\quad\left[\operatorname{FocP} M O R G E N_{i} \text { weet }\left[\operatorname{AgSP} i k \ldots\left[\operatorname{WhP}[\text { hoe laat }]_{j}\left[\operatorname{FocP} t_{i}\left[\operatorname{AgSP} i k t_{i} t_{j} k a n\right]\right]\right]\right]\right]^{7}$

Morgen is assumed to first move to the Spec,FocP position of the subordinate clause before it moves to Spec,FocP in the main clause. Thus, following the initial movement step, it co-occurs with the wh-phrase hoe laat in the $\mathrm{C}$-domain of the subordinate clause.

Turning now to the syntax-discourse interface and to considerations of information structure: gister can be argued to be focalised on the basis of its function in (16), which, in line with Krifka's (2008: 1) definition of focalised phrases, is to indicate alternatives (this type of focus is referred to as "simple focus" in van der Wal 2016). Consider, in this light, (16) as a question arising within the discourse situation below (author's own example):

Speaker A: Johannes Harmse, a twenty-five-year-old man from Pretoria, has been arrested following a spree of violent crime that has had women in the area in a state of anxiety for the past week. On Monday he assaulted a female employee of the Spar in Lynwood, on Tuesday he assaulted a woman at a casino in Hatfield, and yesterday he assaulted a popular female singer at a restaurant in Arcadia.

Speaker B: Die man, gister, watter vrou het hy aangerand?

A simple way to allow for wh-phrases and focalised phrases to co-occur is to allow for additional separate projections that host these elements. Accordingly, Benincà and Poletto

\footnotetext{
${ }^{6}$ A reviewer questions whether (16) is indeed grammatical if gister is focused (i.e. if the resumptive pronoun is omitted). Botha and Oosthuizen (2009) do not comment on whether there is widespread acceptance of this construction. A more careful analysis would thus be required for further work on this topic. However, for the purpose of the discussion in this paper, Botha and Oosthuizen's assessment of the grammaticality of (16) is accepted.

${ }^{7}$ Although, as noted in section 2 of this paper, Hoekstra and Zwart (1994) treat both topicalised and focalised phrases as occurring in Spec,TopP, here we distinguish between TopP and FocP. In the rest of the structure in (17b), Hoekstra and Zwart's original projection labels are used, as they are not important to the point at hand. Additionally, it is noted here that a reviewer questioned whether morgen is indeed focused, rather than serving as a contrastive topic. As before, Botha and Oosthuizen's (2009) original analysis of morgen as a focused element is accepted in this paper, but the need for a more careful analysis of this construction is recognised.
} 
(2004) propose a so-called "focus field" within the left periphery, which they populate with two focus projections. ${ }^{8}$ These are a Contrastive Focus projection (ContFocP), where alternatives are indicated, and an Informational Focus projection (InfFocP), in which new information is provided. Gister, in Speaker B's question above, serves as a source of contrastive focus; that is, "it directs the hearer's attention to something that the speaker wants to make notable in relation to information that is shared between the conversational partners" (Botha and Oosthuizen 2009: 33, author's own translation). Put differently, gister here is referential material that creates a contrast with other phrases that could occupy the same position, such as op Dinsdag 'on Tuesday' or op Maandag 'on Monday' (Botha and Oosthuizen 2009: 33).

If, based on the above arguments, we assume that gister is focalised in (16), then this structure is not compatible with (15), and a further adjustment is necessary. As in Botha and Oosthuizen (2009), for the purposes of this paper, this adjustment will be made in line with Benincà and Poletto (2004), and two kinds of focus will be differentiated: Contrastive Focus and Informational Focus. Within this framework, moved wh-elements are always located in InfFocP, because they refer to "information predicated about the topic", which is "independent" because it is not reliant on other contextual information (Botha and Oosthuizen 2009: 33).

In terms of the ordering of ContFocP and InfFocP, Botha and Oosthuizen (2009: 29) argue that whenever a focalised phrase and a moved $w h$-phrase co-occur, "the wh-phrase must occur lower in the structure than the focalised phrase". Thus, we have the contrast between (18a) and (18b), where in (18a) gister is in ContFocP and the wh-element in InfFocP. In (18b), ContFocP and InfFocP are reversed:

\begin{tabular}{|c|c|}
\hline a. & $\begin{array}{l}\text { [ TopP Die } \text { man }_{i}, \text { [ ContFocP GISTER, [ InfFocP watter vrou [ het hy } \\
\text { the man yesterday which woman have he } \\
\begin{array}{l}\text { aangerand?]]]] } \\
\text { assaulted }\end{array}\end{array}$ \\
\hline b. * & $\begin{array}{l}\text { [ TopP Die } \text { man }_{i} \text {, [ InfFocP watter vrou, [ ContFocP GISTER [ het hyi } \\
\text { the man which woman yesterday have he } \\
\text { aangerand?]]]] } \\
\text { assaulted } \\
\text { "The man, vesterdav, which woman did he assaulted?" }\end{array}$ \\
\hline
\end{tabular}

Botha and Oosthuizen's adjustments result in the template in (19) (only sections relevant to the discussion at hand are shown). As noted at the beginning of this section, the authors argue in the original paper that TopP cannot occur below FocP in Afrikaans, hence the removal of the lower TopP; and that ModP cannot intervene between FocP and the verb, hence its higher position in (19). In addition, in line with Benincà and Poletto (2004), they distinguish between two types of Focus projections: ContFocP and InfFocP, with the latter occurring below the former.

\section{[ TopP [ ModP [ ContFocP [ InfFocP [ FinP [ IP... ]]]]]]}

\footnotetext{
${ }^{8}$ These authors' motivation for proposing a field with unique specifiers rather than simply incorporating multiple FocPs is their contention that "[ $\mathrm{t}$ ]here is a one-to-one relation between position and function" (Benincà and Poletto 2004: 52, cited in Botha and Oosthuizen 2009: 32), which they take to constitute a ban on the recursion of a projection.
} 
Subsequent sections of this paper will revisit (18b). The particular point of interest is why InfFocP, which hosts the wh-element, necessarily occurs below ContFocP. At present, this is simply given as a templatic constraint. However, the aim here is to provide an explanation for this ordering based on independently motivated syntactic principles.

Abels (2012) has also undertaken this task with respect to the structure of the entire Italian CP. His argument, which attempts to derive Rizzi's template on the basis of locality constraints that govern movement to the left periphery, is reviewed in the following section.

\section{Motivating the CP ordering: Abels' (2012) argument from locality}

Abels (2012: 28), in line with the main idea behind this paper, argues that "Rizzi's left peripheral template is undermotivated as a theoretical construct" and proceeds to investigate the possibility of deriving this ordering using long-distance crossing possibilities. He finds that Rizzi's stipulated order can indeed be derived with reference solely to whether an element $a$, originating in the same domain as an element $b$, can cross $b$ in moving out of their shared domain. Abels terms this a "locality" constraint, where locality is understood in the same terms as Relativised Minimality (Rizzi 1990) or Attract Closest (Chomsky 1995). Put simply, locality requires here that if a head attracts a phrase with a particular property to its specifier, it selects the closest phrase with that property.

Abels' argument can be briefly summarised as follows. In a particular domain, assume two elements that can occur, squares $(\square)$ and circles $(\circ)$. In this domain, squares can never precede circles, i.e. the constraint in (20) holds:

$(20) *[\square[\circ \ldots]]$

Assuming that squares and circles arrive in this domain via movement, we can explain the illegality of the ordering in (20) in two ways. Firstly, there may be a templatic constraint that prohibits $\square$ preceding $\circ$ (i.e. the host of $\square$ cannot take the host of $\circ$ as its complement). Alternatively, it may be that there is a ban on $\square$ crossing $\circ$ in the relevant movement process. These two explanations are illustrated in Figure 1 below.

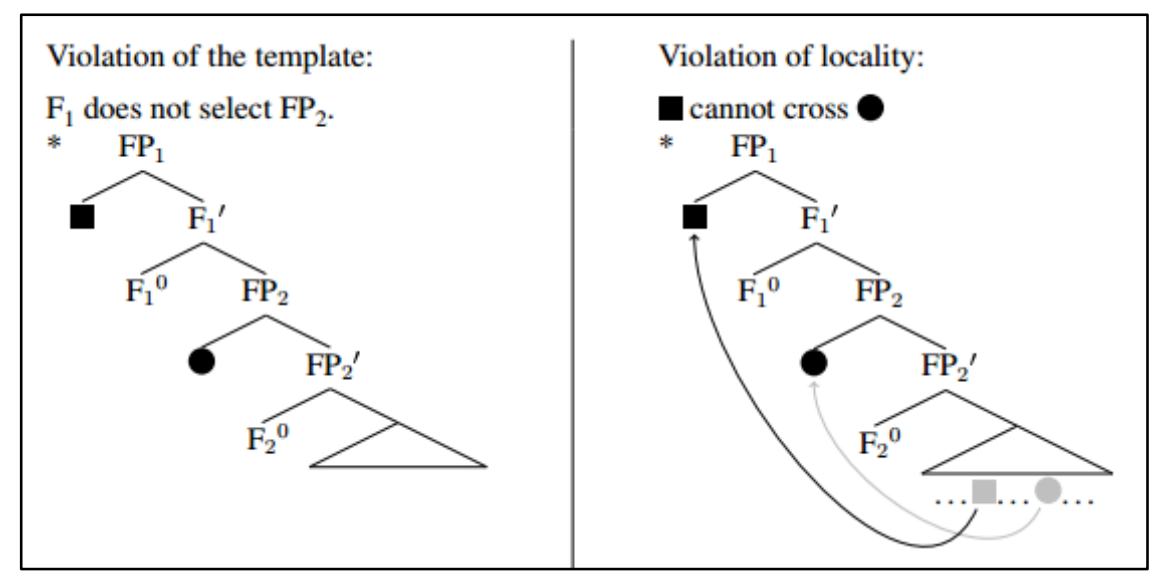

Figure 1: Motivation for the illegality of a certain ordering in the C-domain (Abels 2012:4) 
As long as $\square$ and $\circ$ occur in the same clause, it is impossible to determine whether it is a templatic constraint or an illegal crossing that results in the illicit ordering in (20). However, it is possible to eliminate this confound. Abels notes that it is commonly accepted that templatic constraints apply to local structures, but not to global structures. That is, even if (20) holds, we do not expect (21) to be illicit:

$$
[\square \ldots[\mathrm{CP} \ldots \circ \ldots]]
$$

Consider the structure in Figure 2 below, in which $\square$ precedes $\circ$, but where these elements are in separate clauses.

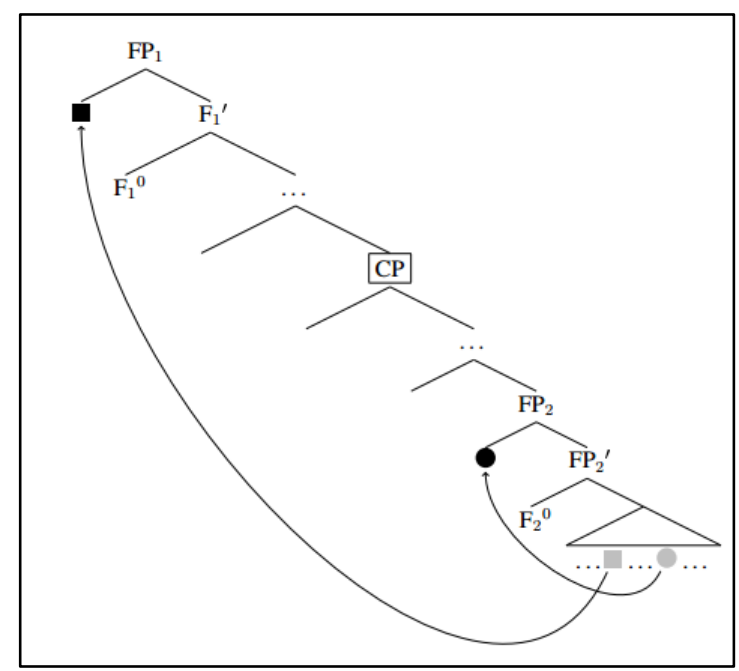

Figure 2: Templatic constraints do not apply across clauses (Abels 2012:6)

If the structure in Figure 2 is acceptable while (20) still holds, then it is evident that there is no ban on $\square$ crossing $\odot$, and so the templatic constraint is necessary to explain why $\square$ cannot precede $\odot$. However, if the structure in Figure 2 is unacceptable and $\square$ cannot precede $\odot$ even when they are in separate clauses, then we do not need to rely on templatic constraints to explain (20). Rather, we can appeal to a locality principle that prevents $\square$ from crossing $\odot$.

Using this line of reasoning, Abels shows that Rizzi's ordering can be derived based on the illegality of structures such as that in Figure 2. A detailed explanation of Abels' methods and findings cannot be provided here. For the purposes of this paper, we focus solely on his discussion of the ordering of $w h$-elements and focalised phrases. In this regard, Abels (2012: 14) notes as follows: "In terms of classical description, $w h$-movement is subject to weak and strong islands... foci give rise to weak islands". This means that a wh-element should not be able to move out of the weak island created by the focalised element. In addition, because "focus movement is weak-island sensitive" (Abels 2012: 14) and wh-elements create weak islands, Abels predicts that extraction of a focalised phrase across a wh-element is illicit (cf. Ross 1967 on island constraints). On the basis of these two premises, which predict that a focalised element can neither precede nor follow a wh-element in the C-domain, he supports Rizzi's contention that a focalised and a wh-element cannot co-occur in the left periphery. 
Thus, neither Abels' (2012) nor Rizzi's (2004) account can account for the ordering we see in (16) and (19). To explain the structure of the Afrikaans CP-template on the basis of established syntactic principles, we must therefore look beyond locality.

Accordingly, the following section looks to locality's antithesis: anti-locality. Grohmann's $(2000,2001,2003)$ theory of anti-locality is first introduced. The templatic order provided for Afrikaans in (19) is then examined through this theoretical lens.

\section{A view from anti-locality}

\subsection{Anti-locality: An introduction}

Grohmann (2000:1), examining movement dependencies within the theoretical framework of the Minimalist Program (MP), presents arguments supporting the idea that "the opposite of moving too far (standard locality) exists also". This operation of 'moving too closely' he terms "anti-locality".

A central aim of the theory of anti-locality is to dispense with stipulations made under GBtheory in favour of an explanation that relies solely on well-formedness conditions - termed "Bare Output Conditions" by Chomsky (1995) - that apply at the levels of Phonological Form (PF) and Logical Form (LF).

Consider the examples in (22)-(24) below (based on Grohmann 2001: 89), where (a) in each case is the ungrammatical construction resulting from the derivation in (b).

$$
\text { a. * John likes }{ }^{9}
$$

b. $\quad\left[{ }^{\mathrm{P}} \mathrm{J}\right.$ John $v[\mathrm{vp}$ likes John $\left.]\right]$

\section{a. * Him likes she/her.}

b. [ TP him T [ AgrOP him AgrO [ ${ }^{\mathrm{PP}}$ him $v$ [vP likes she/her ] ] ] ]
a. * Who, did John see?
b. [ TopP who Top [ FocP whe (did-) Foc [TP John saw/see... (whø)...] ] ]

In (22), one thematically-marked element moves to another theta position. In (23), movement from one Case position - in this case, AgrOP, where him checks accusative - to another, where him checks nominative, is illicit. In (24), once the wh-element has moved to FocP producing Who did John see?, it cannot move further to TopP. Under GB theory, the illicitness of these structures could be explained with recourse to the Theta-Criterion in (22), the Case Filter in (23), and the Wh-Criterion in (24). However, dispensing with these explanations, Grohmann notes that another characteristic of (22)-(24) that may be able to account for their ill-formedness is the "too closely related positions" involved in all of the movement steps that are indicated.

\footnotetext{
${ }^{9} \mathrm{~A}$ reviewer points out that this construction is acceptable in a number of English varieties, where the direct object of like is something contextually salient. However, as a result of the derivation in (b), where the object of likes is "John", (a) is still ungrammatical.
} 
He therefore proposes the hypothesis in (25):

Anti-locality hypothesis: Movement must not be too local.

Given Grohmann's proposal in (25), it remains to be defined what exactly "too local" movement is. This definition comes in the form of his division of the clause into three "Prolific Domains", an explanation of which is given below.

A Prolific Domain is (i) a contextually defined part of the computational structure, which (ii) provides the interfaces with the information relevant to the context, and (iii) consists of internal structure interacting with the derivational operations. According to this definition, Grohmann (2001: 90-91) divides the clause into three parts: i) the $\theta$-domain, "the part of the derivation where $\theta$-relations are created"; ii) the $\phi$-domain, "the part of the derivation where agreement properties are located"; and iii) the $\omega$-domain, "the part of the derivation where discourse information is established".

These domains are said to be "prolific" because they incorporate a finely articulated structure. Thus, the $\theta$-domain includes $\nu \mathrm{P}>\mathrm{VP}$, the $\phi$-domain includes TP $>$ AgrOP, and the $\omega$-domain includes TopP > FocP. Furthermore, they are characterised as "domains" because they "denote particular (and unique) part[s] of the structure characterized by contextual information" (Grohmann 2001: 91). This tripartite division of the clause is noted to be nothing new and therefore relatively uncontroversial: a similar proposal can be found in e.g. Chomsky's (1986) division of [ COMP [ INFL [ VP ]]].

Above it was argued that, ideally, the proposed ban on too-local movement should be explained with reference to Bare Output Conditions. In order for such an explanation to hold, there must be a restriction on too-local movement either at PF or LF. Grohmann (2001: 91) formulates the condition resulting in a ban on too-local movement under the label of the "Condition on Domain Exclusivity" (CDE), given below in (26):

Condition on Domain Exclusivity (CDE)

An object $\mathrm{O}$ in a phrase marker must have an exclusive Address Identification (AI) per Prolific Domain, unless duplicity [i.e. the doubling of $\mathrm{O}-\mathrm{RB}$ ] yields a drastic effect on the output.

i) An AI of $\mathrm{O}$ in a given Prolific Domain is an occurrence of $\mathrm{O}$ in that Prolific Domain at LF.

ii) A drastic effect on the output is a different realization of $\mathrm{O}$ at PF.

Put simply, the CDE states that only one copy of an object O can occur within a Prolific Domain unless the lower copy of an element within a single Prolific Domain is realised differently at $\mathrm{PF}$. This change in PF-realisation is achieved through Copy Spell Out, where an object $\mathrm{O}$ is replaced with $\mathrm{X}$, "an item from the inventory of a given language that looks different, but can act as if it were O" (Grohmann 2000: 115). Returning to the example given in (22) above, the $\mathrm{CDE}$ can be illustrated with reference to the appearance of a reflexive anaphor in (27b). (27c) presents another alternative: the presence of a focused "John" that clearly refers to someone other than the subject.

$$
\text { a. * John likes. }
$$




\section{b. John likes himself. \\ c. John likes JOHN.}

Because the movement of John within the $\theta$-domain is too local, (27) can only be rescued if Copy Spell Out intervenes so that the lower copy of "John" is replaced by an item that looks different, but can act as if were John, i.e. himself or focused JOHN.

Anti-locality is thus proposed to be a PF-condition: an object $\mathrm{O}$ at LF must be coupled with a unique PF-realisation. Thus, generally "an expression must have one and only one phonological occurrence in a given Prolific Domain, whether it is pronounced or not" (Grohmann 2001: 91).

Having briefly introduced the mechanisms of a theory of anti-locality, the next section returns to the question of ordering within the Afrikaans $\omega$-domain.

\subsection{An anti-locality explanation of an illicit ordering within the Afrikaans CP}

The remainder of this paper focuses on one of the illicit orderings within the Afrikaans CP covered above, which involves material intervening between a moved $w h$-element and the verb. This illicit configuration is illustrated in (18b), repeated below for convenience:

(18b) *Die man, watter vrou, GISTER het hy aangerand? that man which woman yesterday has he assaulted

The structure of such an ungrammatical sentence would be as follows:

$$
\text { [ TopP... [ XP wh-element [ ContFocP... [ FinP... ]]]] }
$$

Botha and Oosthuizen (2009) do not explore the reason for (18b)'s ungrammaticality. Instead of relying on the "theoretically undermotivated" argument that such a configuration is not allowed due to a templatic constraint, this section proposes an explanation based on Bare Output Conditions, making use of Grohmann's theory of anti-locality.

This explanation rests on three premises: (i) the moved wh-element is moved to the Spec of InfFocP, which is adjacent to the verb in Fin; (ii) a configuration involving intervening material between the $w h$-element and the verb always results from movement of the $w h$-element to a higher position in the CP; (iii) this movement is 'too local', and therefore results in ungrammaticality. The remainder of this section deals with each of these premises in turn.

\subsubsection{The moved $w h$-element is located in Spec,InfFocP}

In (18a), the wh-element watter vrou is a request for new information, and so is expected to occur in InfFocP, which, in Botha and Oosthuizen's structure in (19), is adjacent to FinP, which hosts the verb. The claim that the $w h$-element occupies a FocP is supported by Grohmann (2003: 20), who notes that "[w]h-phrases, being inherently focused, target FocP", and Lasnik and Uriagereka (1988, cited in Grohmann 2003: 24), who state that " $[\mathrm{t}]$ he descriptive generalization seems to be that a [w]h-phrase cannot undergo [t]opicalisation". This is illustrated in (29) below: 
The presence of a resumptive pronoun renders (29) ungrammatical, as was shown to be the case for focalisation in Afrikaans earlier in the paper.

The remaining option for the position of the moved wh-element would be ModP. However, such a configuration is implausible in the case of direct-object $w h$-elements, which are evidently not modifiers and therefore could not reasonably be said to occupy ModP. ${ }^{10}$ Thus, we conclude that the moved wh-element occupies Spec,InfFocP in (18a).

(18a) therefore has the structure in (30) below:

$$
\text { [ TopP Die man [ ContFocP GISTER [ InfFocP watter vrou }[\text { FinP het }[\text { IP hy aangerand? }]]]]]^{11}
$$

\subsubsection{The intervening material between the $w h$-element and the auxiliary verb is the result of movement of the $w h$-element}

Here, we proceed from the above argument that the moved wh-element in (18a) indeed occurs in Spec,InfFocP, adjacent to FinP. From this, it follows that within an expanded CP structure, any intervening material between the wh-element and the verb in FinP is the result of leftward movement of the $w h$-element. (This is if we abandon the possibility of additional adjunction to Spec,InfFocP, which Grohmann indeed does, as his theory posits unique specifiers.)

Thus, the illicit (18b) has the derivational structure in (31) below:

$$
\begin{aligned}
& \text { [ TopP Die man [ XP watter vrou [ ContFocP gister [ InfFocP atter wrou [ FinP het [ IP hy } \\
& \text { aangerand ]]]]]] }
\end{aligned}
$$

\subsubsection{Movement of the $w h$-element within the $\mathrm{CP}$ is disallowed because such movement is 'too local'}

We see in the above derivational structure that the wh-element moves leftwards over gister to another, higher functional position in the CP (for our purposes, it is not important which one). This movement is an example of Grohmann's illicit movement within the $\omega$-domain. Following the upward movement of watter vrou, there are now two copies of that element within the Prolific Domain, violating the CDE and thereby resulting in ungrammaticality. ${ }^{12}$

\footnotetext{
${ }^{10}$ Furthermore, if moved $w$-elements did occupy TopP or ModP, it would be necessary to posit a covert operator occupying Spec,FocP and bearing a strong tense feature in order to attract the auxiliary and bring about the obligatory subject-verb inversion. Because it is undesirable to assume the existence of invisible elements in the structure unless absolutely necessary, this should be a last-resort explanation.

${ }^{11}$ A reviewer notes the alternative possibility that the $w h$-element could occupy Spec,FinP. We acknowledge this possibility, but as it does not have consequences for the main analysis presented here, it is set aside.

${ }^{12}$ Grohmann (2003: 21) notes that the inability of the $w h$-element to move further in the CP might also be explained with reference to "some version of Greed", but that Greed cannot explain all cases of illicit movement within Prolific Domains. A Greed-based explanation is not considered here.
} 


\section{Concluding remarks}

This paper explored the possibility of explaining one aspect of the structure of the Afrikaans $\mathrm{CP}$ on the basis of an adjusted version of Rizzi's (2004) six-way split of that domain and Grohmann's (2000, 2001, 2003) theory of anti-locality. In line with Abels (2012), it was argued that a mere stipulation of licit and illicit orderings of projections within the $\mathrm{CP}$ is not sufficient, and that it is desirable to use independently motivated syntactic principles to account for this ordering. Abels' attempt to use the principle of locality to accomplish this was explored, and subsequently an explanation relying on anti-locality was proposed for one particular instance of illicit ordering within the Afrikaans CP.

Because of the present paper's limited scope, the analysis presented in the previous section is underdeveloped. Further research might consider under what conditions Grohmann's 'rescue operation' of Copy Spell Out occurs, and why it does not occur in the derivation of (18b). It would also be worthwhile to investigate whether an anti-locality explanation can account for other illicit constructions in Afrikaans involving closely related positions. Ultimately, the paper leaves open many questions for further research. It does, however, contribute a more detailed consideration of one issue raised in Botha and Oosthuizen (2009).

\section{References}

Abels, K. 2012. The Italian left periphery: a view from locality. Linguistic Inquiry, 43(2): 229254.

Aboh, E.O. 1999. From the syntax of Gungbe to the grammar of Gbe. Doctoral dissertation. University of Geneva.

Badan, L. and F. Del Gobbo. 2011. On the syntax of topic and focus in Chinese. In P. Benincà and N. Munaro (eds.), Mapping the left periphery. Oxford: Oxford University Press. pp. 63-90.

Benincà, P. 2001. The position of Topic and Focus in the left periphery. In G. Cinque and G. Salvi (eds.). Current studies in Italian syntax: essays offered to Lorenzo Renzi. Oxford: Elsevier. pp. 39-64.

Benincà, P. and C. Poletto. 2004. Topic, focus and V2: defining the CP sublayers. In L. Rizzi (ed.). The cartography of syntactic structures. New York: Oxford University Press. pp. 52-75.

Botha, M. and J. Oosthuizen. 2009. Die struktuur van die linker-sinsgrens in Afrikaans. Stellenbosch Papers in Linguistics Plus, 37: 1-68.

Chomsky, N. 1986. Barriers. Cambridge, Mass: The MIT Press.

Chomsky, N. 1995. The minimalist program. Cambridge, Mass: The MIT Press.

Frascarelli, M. and R. Hinterhoelzl. 2007. Types of topics in German and Italian. In K. Schwabe and S. Winkler (eds.). On information structure, meaning and form. Amsterdam: Benjamins. pp. $87-116$. 
Grohmann, K. K. 2000. Prolific peripheries: A radical view from the left. Doctoral dissertation. University of Maryland, College Park.

Grohmann, K. K. 2001. On predication, derivation and anti-locality. ZAS Papers in Linguistics, 26: 87-112.

Grohmann, K. K. 2003. Prolific domains: On the anti-locality of movement dependencies. Amsterdam: Benjamins.

Hoekstra, E. and J-W. Zwart. 1994. De structuur van CP. Available online: http://www.dbnl.org/tekst/_spe011199401_01/_spe011199401_01_0013.php. (Accessed 31 August 2017).

Krifka, M. 2008. Basic notions of information structure. Acta Linguistica Hungarica, 55(3): 243-276.

Neeleman, A., E. Titov, H. van de Koot and R. Vermeulen. 2009. A syntactic typology of topic, focus and contrast. In J. van Craenebroeck (ed.). Alternatives to cartography. Berlin: de Gruyter. pp. 15-1.

Oosthuizen, J. 1994. 'n Verdere komplement vir COMP. In C. van der Merwe, H. Waher and J. Hambidge (eds.). Rondom Roy: studies opgedra aan Roy H. Pheiffer. Cape Town: University of Cape Town, Department of Afrikaans and Dutch.

Paul, Ileana. M. 2000. Malagasy clause structure. Doctoral dissertation. McGill University.

Radford, A. 2006. Minimalist syntax revisited. Available online: http://www.public.asu.edu/ gelderen/Radford2009.pdf (Accessed 31 August 2017).

Rizzi, L. 1990. Relativized minimality. Cambridge, Mass: MIT Press.

Rizzi, L. 1997. The fine structure of the left periphery. In L. Haegeman (ed.), Elements of grammar Dordrecht: Springer. pp. 281-337.

Rizzi, L. 2004. Locality and left periphery. In A. Belletti (ed.). Structures and beyond. Oxford: Oxford University Press. pp. 223-251.

Ross, J. R. 1967. Constraints on variables in syntax. Doctoral dissertation. MIT.

Van der Wal, J. 2016. Diagnosing focus. Studies in Language, 40(2): 259-301. 